\title{
AN EXPLORATORY STUDY OF WILLINGNESS OF THE FACULTY OF AGRICULTURE STUDENTS AT MANSOURA UNIVERSITY TO PARTICIPATE IN PROVIDING THE AGRICULTURAL EXTENSION AND COMMUNITY SERVICES. Ramadan, A. M. A.
}

Agricultural Extension and Rural Society, Faculty of Agriculture, Mansoura University

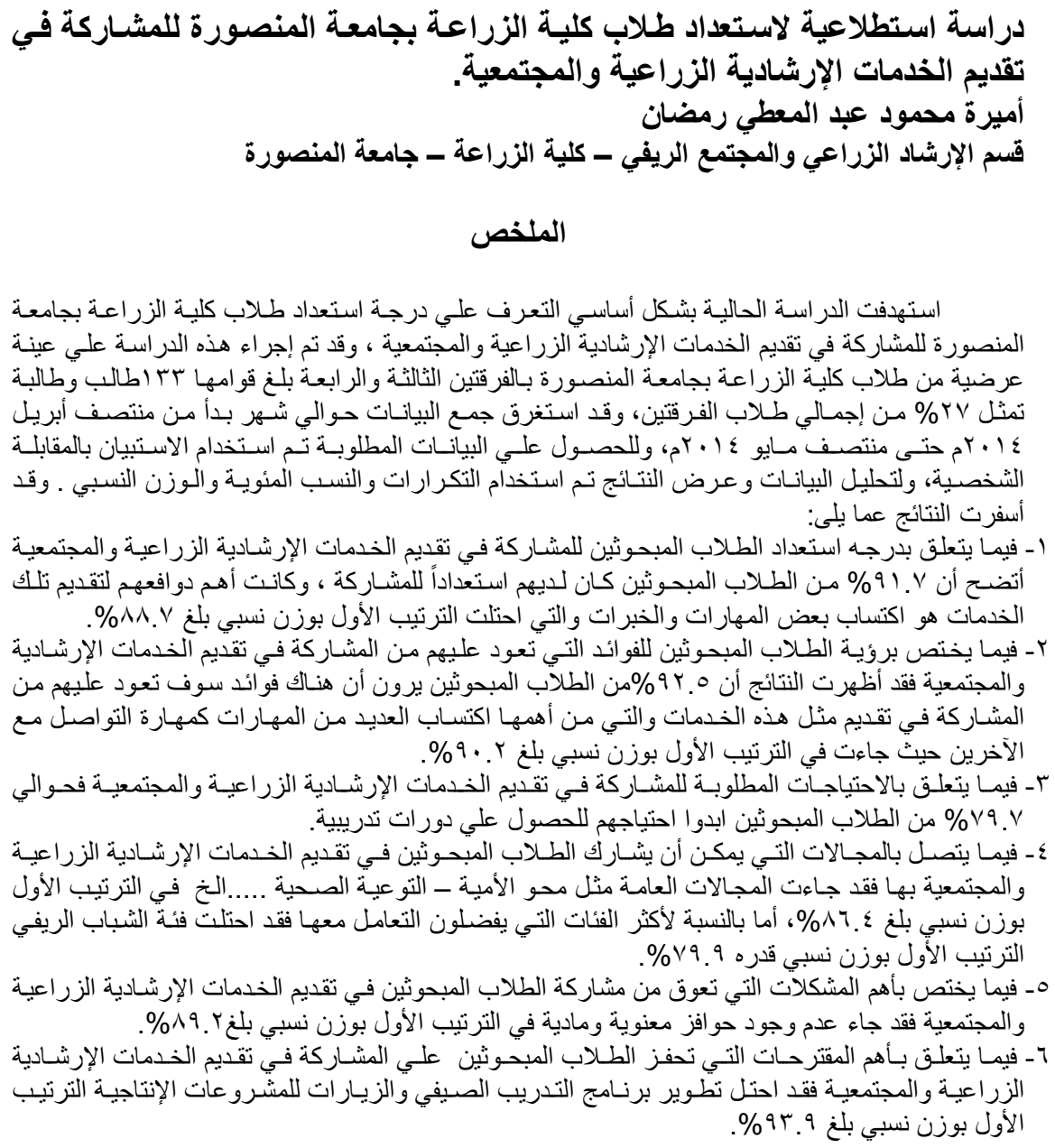


Ramadan, A. M. A.

\section{المقدمة والمشكلة البحثية}

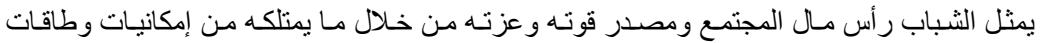

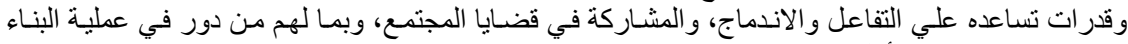

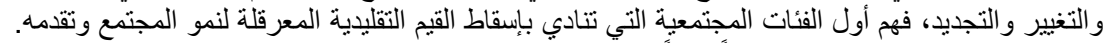

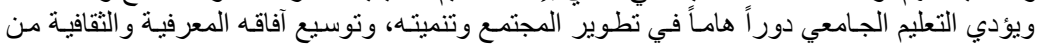

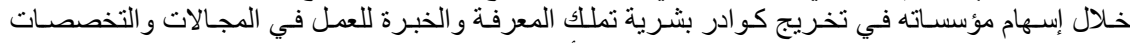

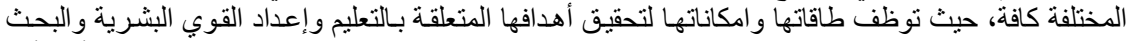

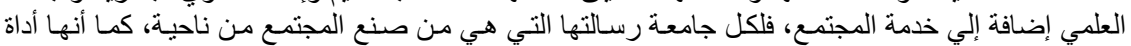

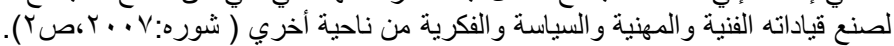

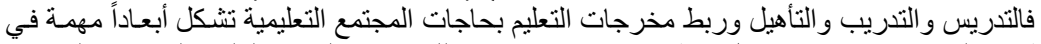

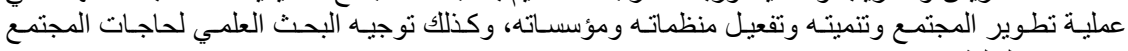

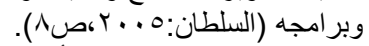

ولكن رغم ذللك نجد أن هناك العديد من المعوقات التهات التي تحول دون قيام الثباب بدور فعيال في تتمية

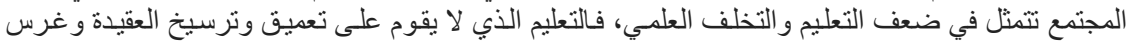

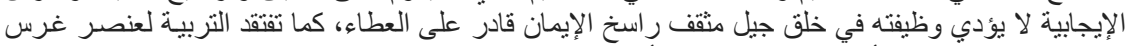

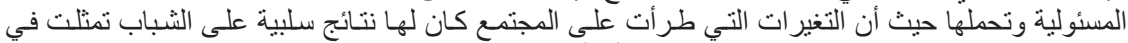

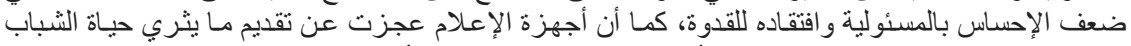

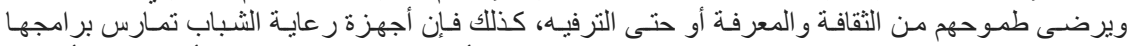

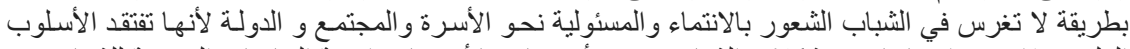

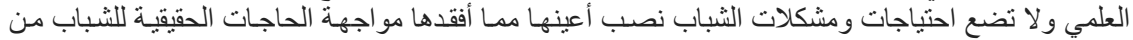

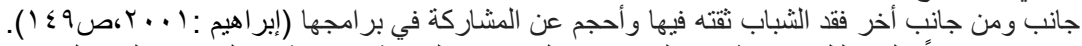

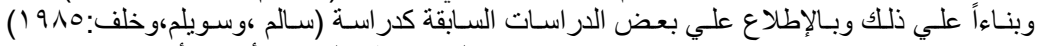

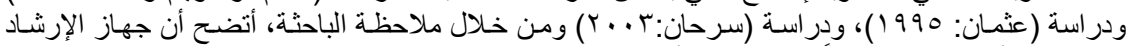

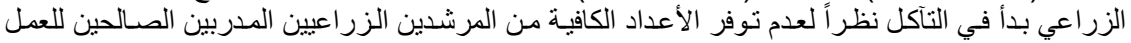

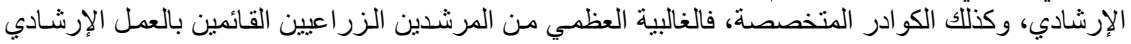

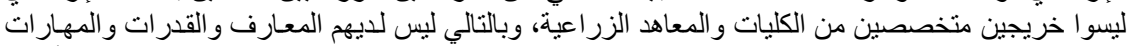

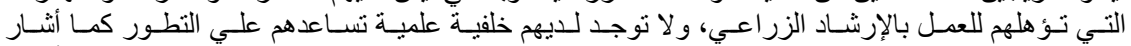

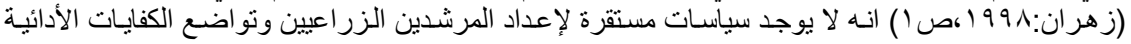

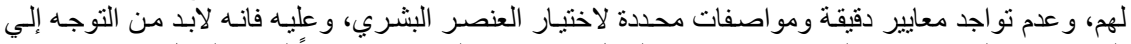

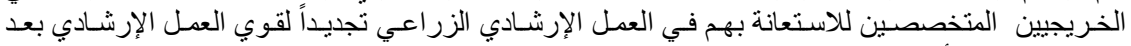
تدرييهم وتاهليهم أثناء سنوات الدار استة بالكلية.

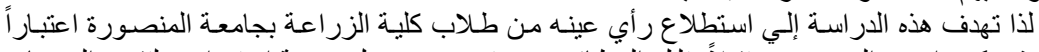

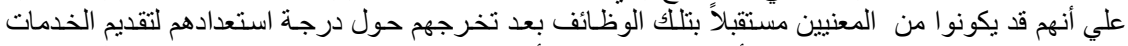

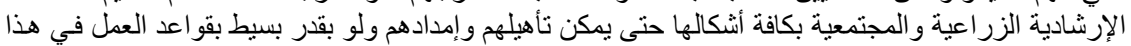

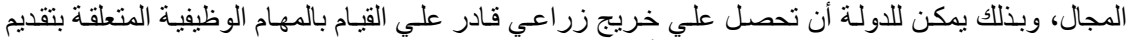
الخدمات الإرشادية الزراعية ولألمنمعية علي أسس علمية وتندريبية سلمية.

\section{الاستعراض المرجعي للاراسة}

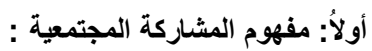

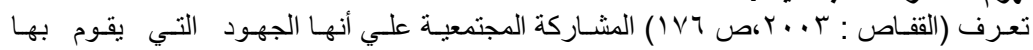

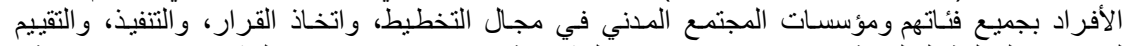

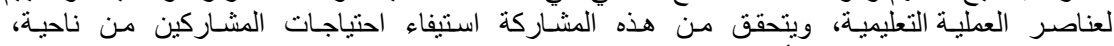
وتحقيق الصالح العام من ناحية أخرى. 


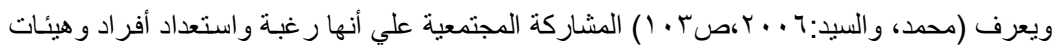

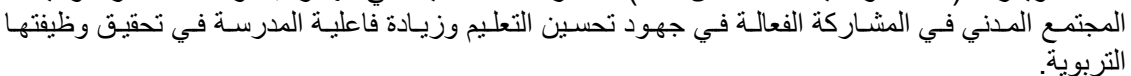

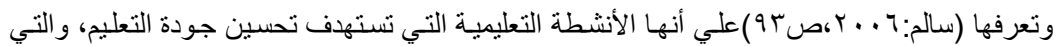

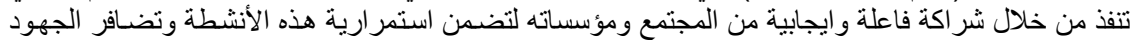

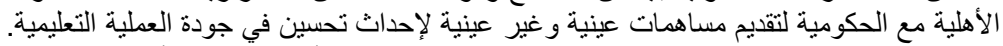

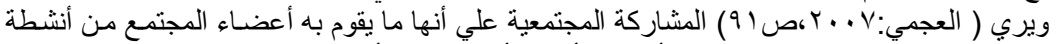

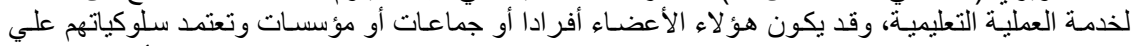

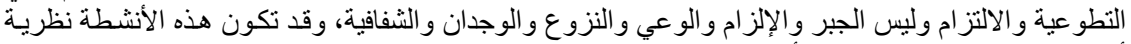

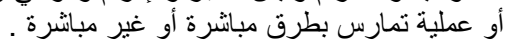

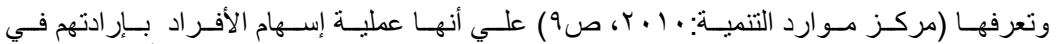

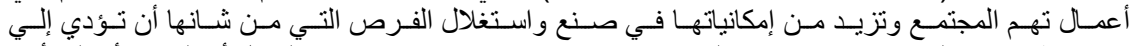

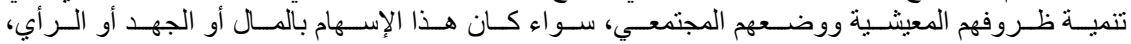

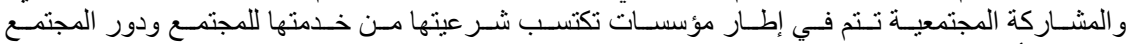

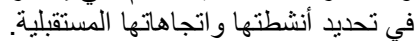

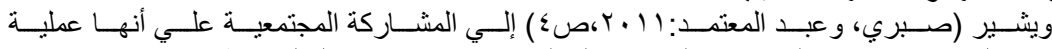

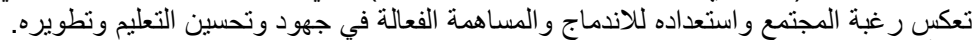

ثانياً: أهمية وأهداف المشاركة المجتمعية:

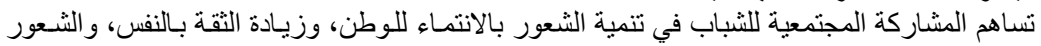

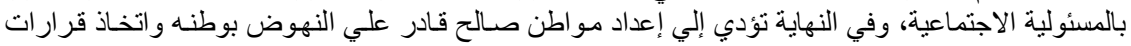

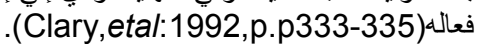

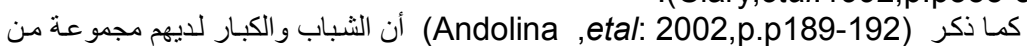

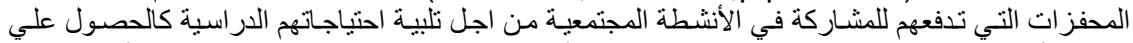

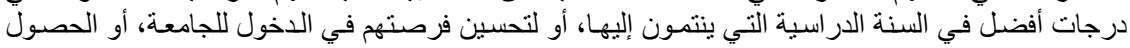

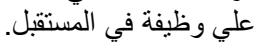

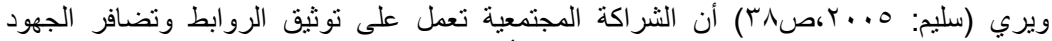

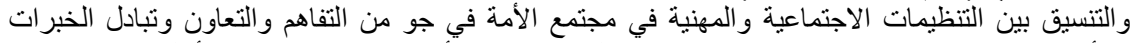

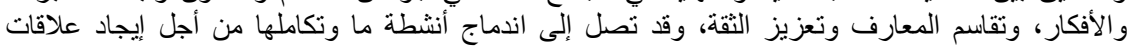

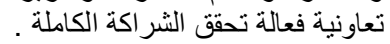

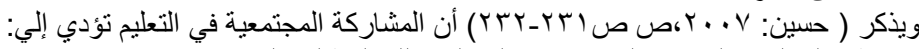

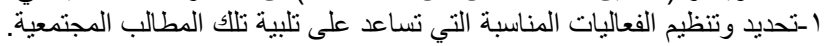

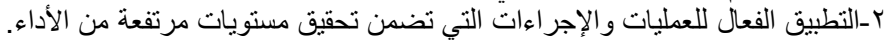

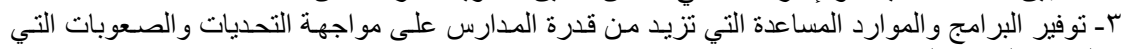
يمتلىئ بها العصر البر الحديث. ـ ـالمساعدة على توفير العديد من الخبر ات و الاداءات التي تمثل قيمة كبرى للمدارس، وتسـاهم في تحريك

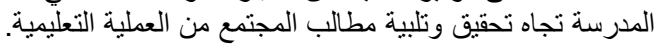

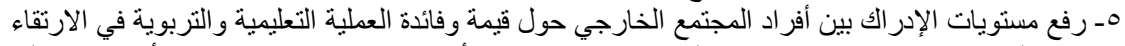

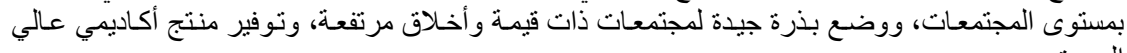

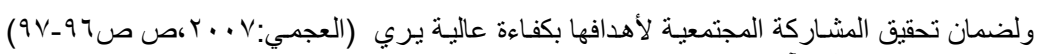
الجودة.

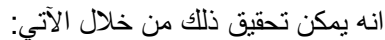

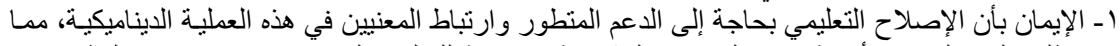

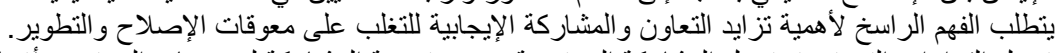

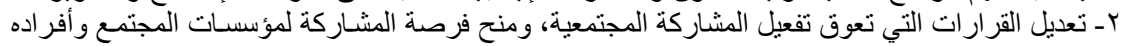

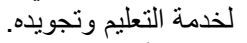

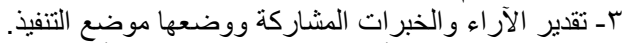

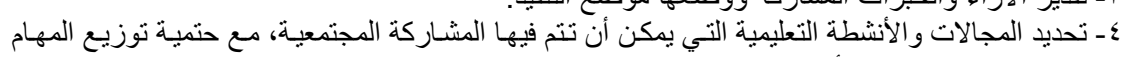

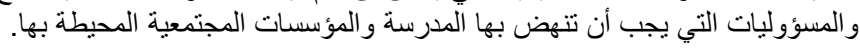


Ramadan, A. M. A.

هـ تبنـي وزارة التربية والتعليم لسياسـة اللامركزيـة في إدارة التعليم فتتمكن كل إدارة تعليميـة ومدرسية من

تحقيق التفاعل الإيجابي مع مجتمعها وبيئتها المحلية المحيطة المئة

ثالثاً: معوقات المشاركة المجتمعية:

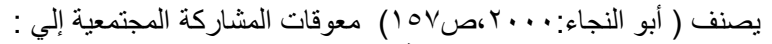

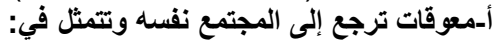

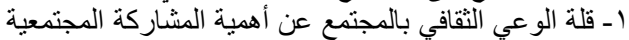

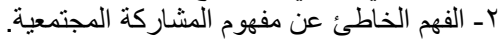

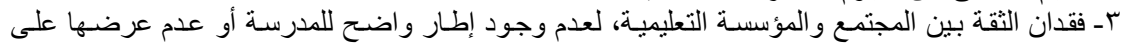

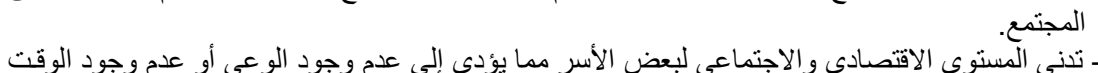
الكافي للمشاركة المجنمعية.

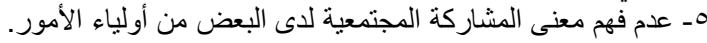

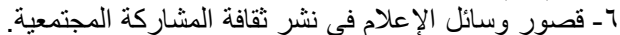

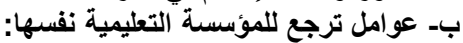

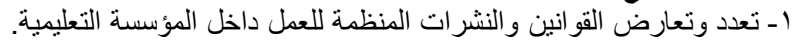

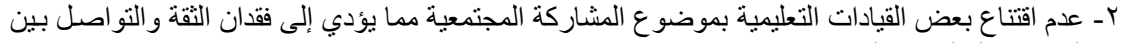

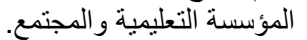

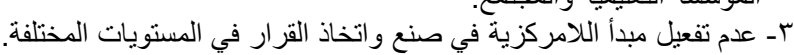

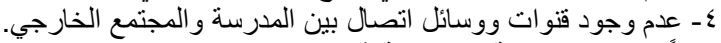
رابعاً: تقويم المشاركة المجتمعية في التعليم المتاني

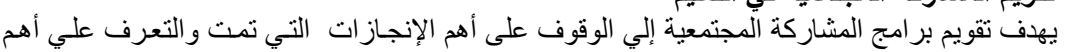

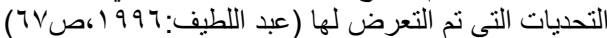

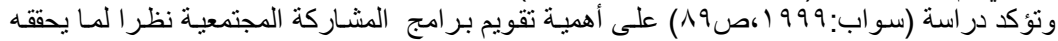

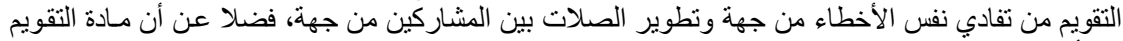

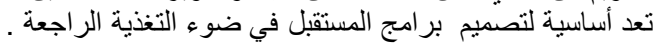

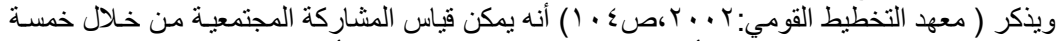

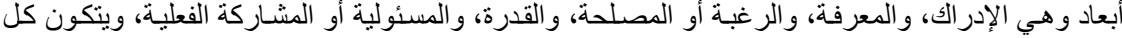

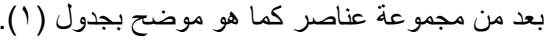

جدول (1) (1) أبعاد قياس المثاركة المجتمعية.

\begin{tabular}{|c|c|}
\hline عناصره & 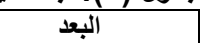 \\
\hline 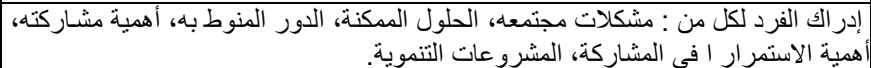 & |الإدر اك \\
\hline المشروفة الفرد لكتل من : مشكلات مجتمعاه، الحلول الممكنة، الدور المنوط به، أدوار الآخرين، & | المعرفة \\
\hline 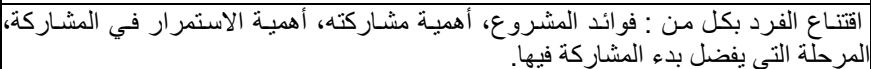 & |الر غبة/المصلحة \\
\hline نو افر الوقت الكافي، استعداد الفرد في المشاركة، تو افز الإمكانيات المادية و العينية للفرد. & 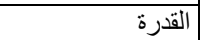 \\
\hline إبداء الر أي، حضور الآجتماعات، عضوية اللجان. & \multirow{4}{*}{ |الفعلية المسئولية/المشاركة } \\
\hline الاشتر الك بالجهر، بالآلات و المعدات، بالمال، بالأرض. & \\
\hline تقايم مقترحات، حل مشكلات، إضافة تعديلات. & \\
\hline الاستمر ارية: مشابعة المشروع بعد تنفيذه، إدارة المشروع، صيانته، حث الآخرين على & \\
\hline
\end{tabular}




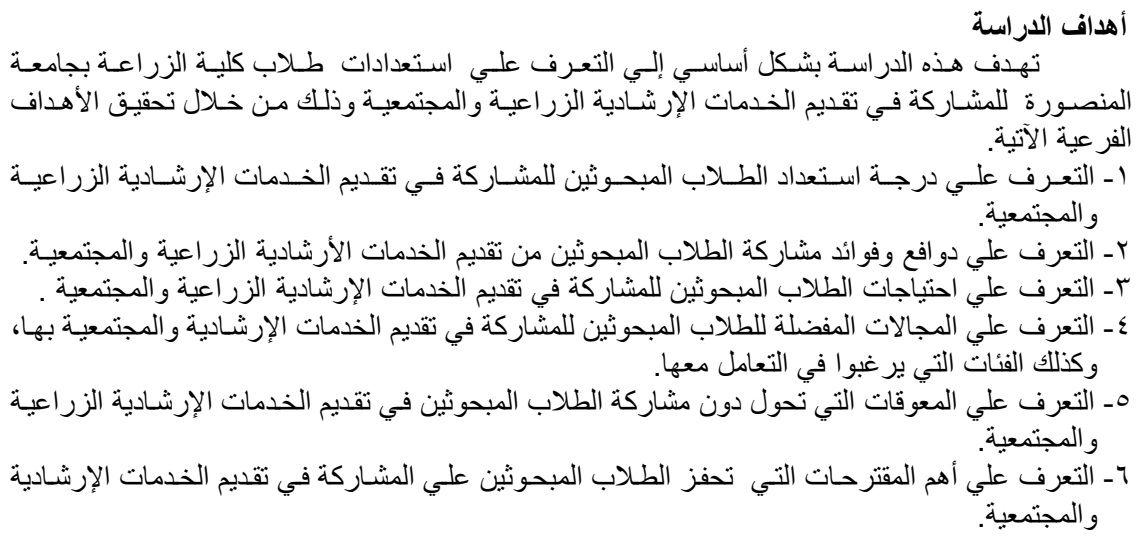

\section{الطريقة البحثية}

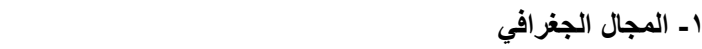

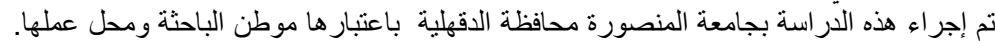
r- المجال البشري

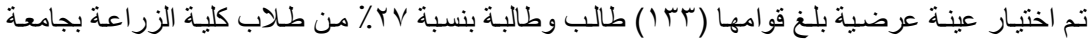

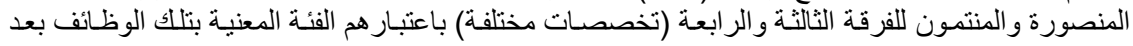

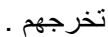
ب- المجال الزمني استغرقت عمليّة جمع البيانات حو الي شهر ، بدأت من منتصف أبريل ــ ا ـ بم و انتهت في منتصف مايو

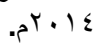
عـ أداة جمع البيانات للحصـول علـي البيانـات اللازمـة لتحقيق أهداف الدر اسـة، تم استخدام الاستبيان بالمقابلـة الثخصية، وقد

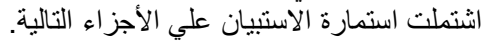

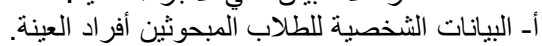

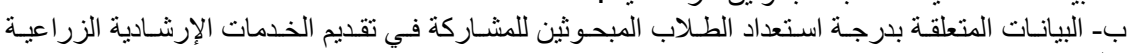
و المجتمعية ودو افع مشار كتهر.

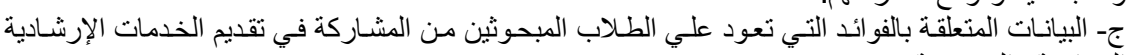
الزر اعية والبيان المتمعية.

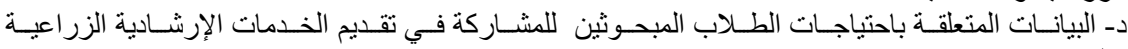
و والمجتمعية.

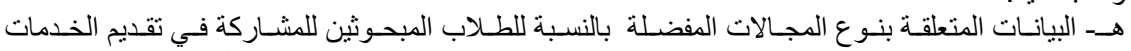

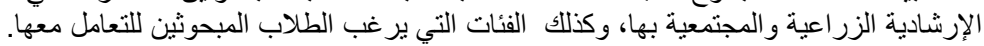

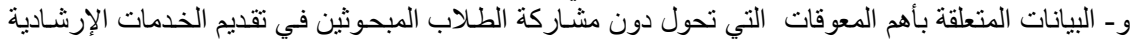
الزر اعية و المجتمعية. ز - البيانات المتعلقة بأهم المقترحات التماتة التي تحفز الطلاب المبحوثين علي المشاركة في تقديم الخدمات الإرشادية الزر الاعية والمجتمعية.

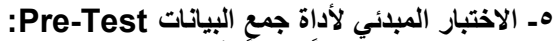

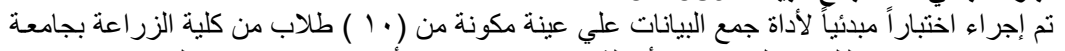

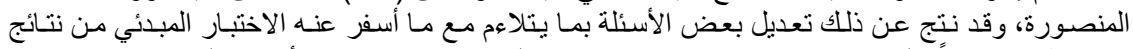

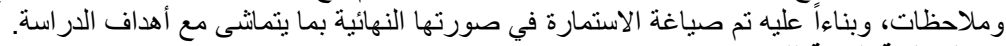
T- المعالجة الكمية للبيانات:

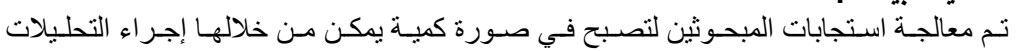
الإحصائية لاستخلاص نتائج الدراسة، وذلك الك على النحو التنالي : 
Ramadan, A. M. A.

أـ تحديد درجة استعاد الطلاب المبحوثين للمشاركة في تقديم الخدمات الإرشادية الزراعية والمجتمعيـة:

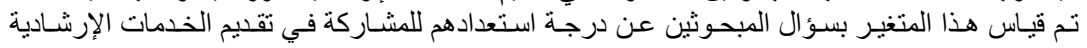

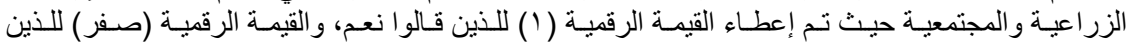

بـ تحديد دوافع مشاركة الطلاب المبحوثين في تقليم الخدمات الإششادية الزراعية والمجتمعية:

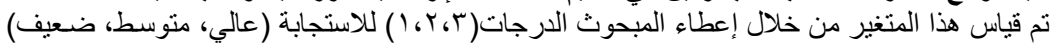

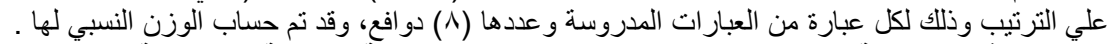

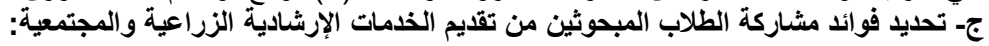

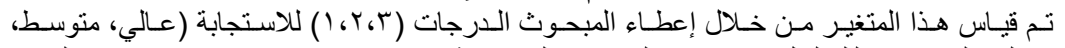

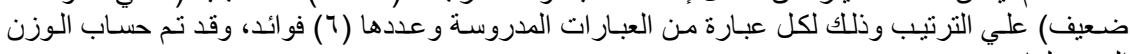
النسبي لها

دـ تحبيد احتياجات الطلاب المبحوثين للمشاركة في تقديم الخذمات الإرشادية الزراعية والمجتمعية:

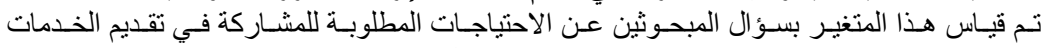

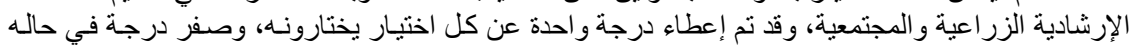

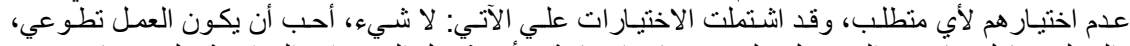

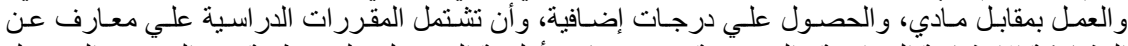

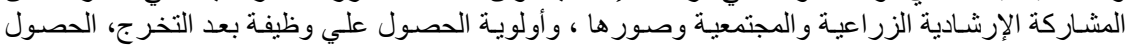
علي دورات تدريبية عن موضو عات الندات المشاركة. هـ تحديد المجالات المفضلة بالنسبة للطلاب المبحوثين للمثـاركة في تقديم الخدمات الإرشادية والمجتمعية

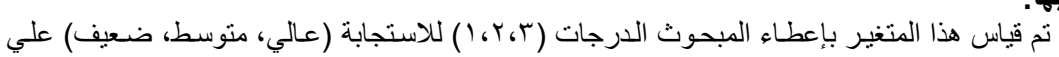

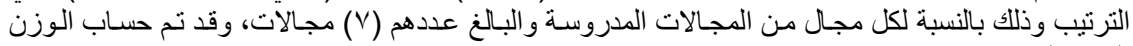
والنسبي لها.

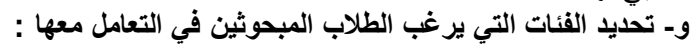

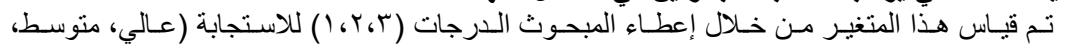

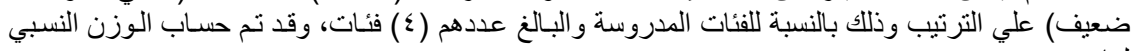

زـ ـ تحديد المعوقات التي تحول دون إتمام المشاركة في تقديم الخدمات الإرشادية الزراعية والمجتمعية:

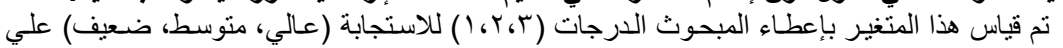

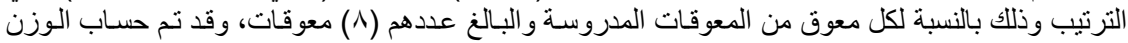
حـ تحبيد المقترحات التي تحفز الطلاب المبحوثين علي المشاركة في تقديم الخدمات الإششادية الزراعية

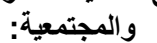

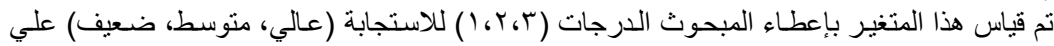

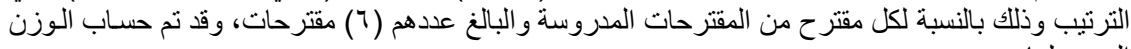
النسبي لها.

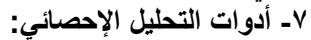

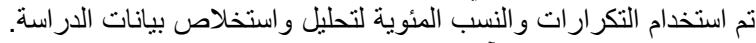

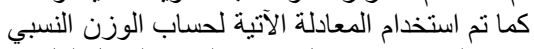
عدد المبحوثين في كل فئة × الوزن المقابل لكئ لكل فئة

إجمالي عدد المبحوثين × أكبر وزن 


\section{النتائج ومناقشتها}

يعرض هذا الجزء أهم النتائج التي توصلت إليها الدراسة كما يلي: أولاً: الخصائص الثخصية للطلاب المبحوثين:

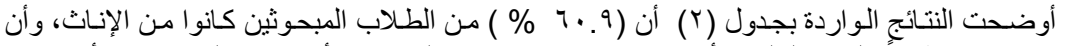

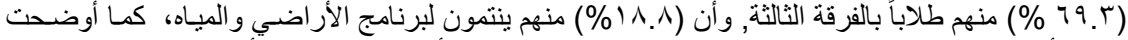

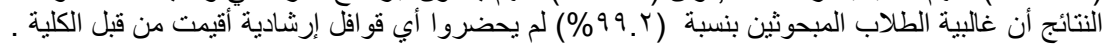

جدول (r): توزيع الطلاب المبحوثين وفقاً للخصائص الشخصية

\begin{tabular}{|c|c|c|}
\hline$\%$ & العدد & المتغيرات المدروسة \\
\hline \multicolumn{3}{|r|}{ 1- النوع } \\
\hline r9.1 & or & ذكر \\
\hline $7 \cdot .9$ & $\wedge 1$ & أنثي \\
\hline \multicolumn{3}{|r|}{ r- - الفرقة الدراسية } \\
\hline 79.1 & $9 T$ & الفرقة الثالثة \\
\hline$r \cdot . \wedge$ & «1 & الفرقة الر ابعة \\
\hline \multicolumn{3}{|r|}{ r- التخصص } \\
\hline 17.0 & Tr & هندسة زر اعية ونظم حيوية \\
\hline IV.r & rT & انتاج حيو اني وداجني وسمكي \\
\hline$r . \wedge$ & 0 & الإنتاج النباتي \\
\hline 10.1 & r) & لعلوم الاقتصادية و الاجتماعية \\
\hline 11.1 & ro & علوم الأر اضي \\
\hline Ir.* & 17 & علوم وتكنولوجيا الأغذية \\
\hline 9.1 & 14 & التقنية الحيوية الزراعية \\
\hline 7." & $\Lambda$ & وقاية النبات \\
\hline \multicolumn{3}{|r|}{ ـ - حضور القوافل الإرشادية } \\
\hline$\because .10$ & 1 & 20 \\
\hline 99.10 & ITr & $\bar{y}$ \\
\hline $1 \cdots \cdots$ & $1 \pi$ & الإجمالي \\
\hline
\end{tabular}

ثانياً: استعداد الطلاب المبحوثين للمشاركة في تقديم الخدمات الإرشادية الزراعية والمجتمعية:

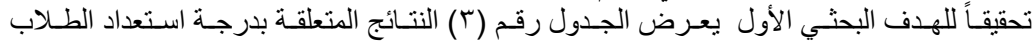

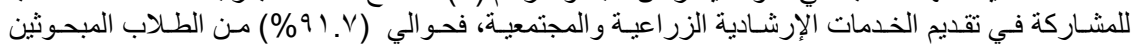

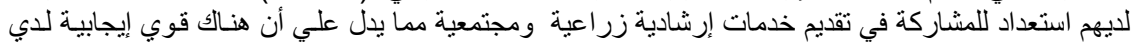

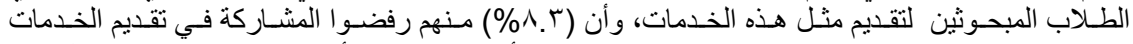

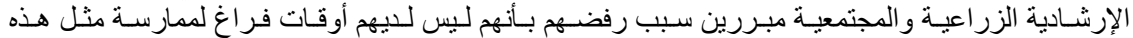

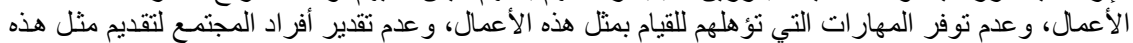

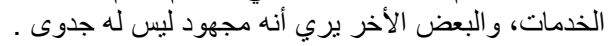


Ramadan, A. M. A.

جدول (ب): توزيـع الطلاب المبحوثين وفقاً لاستعدادهم للمشـاركة في تقديم الخدمات الإرشـادية الزراعية والمجتمعية

\begin{tabular}{|c|c|c|}
\hline$\%$ & 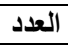 & الاستعداد للمشاركة \\
\hline \multicolumn{3}{|c|}{ 1- الاستعداد للمشاركة في تقديم الخدمات الإرشادية الزراعية والمجتمعية } \\
\hline $91 . \mathrm{V}$ & ITY & نعمم \\
\hline$\Lambda . r$ & 11 & $y$ \\
\hline \multicolumn{3}{|r|}{ r ـ أسباب الرفض في المشاركة } \\
\hline$\leqslant 0 . \leqslant$ & 0 & - عدم وجود وقت فراغ \\
\hline rV.Y & $r$ & - عم توفر المهارات \\
\hline 11.1 & $r$ & - عدم تقدير أفراد المجتمع لتقديم هذه الخدمات \\
\hline 9.. & 1 & 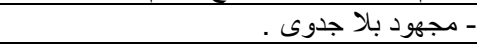 \\
\hline $1 \cdots \cdots$ & Ir & 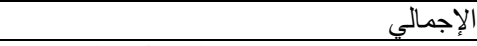 \\
\hline
\end{tabular}

ثالثثاً: دوافع مشاركة الطلاب المبحوثين في تقديم الخدمات الإرشادية الزراعية والمجتمعية:

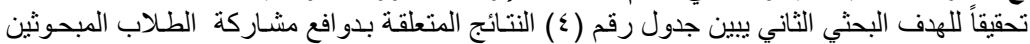

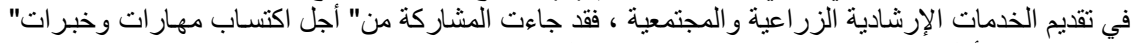

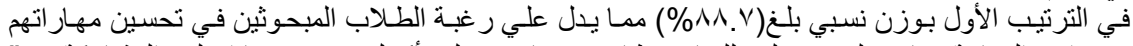

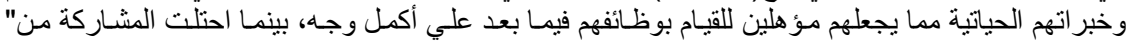

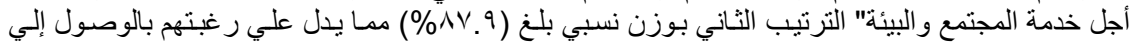

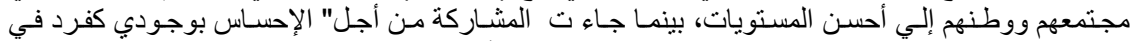

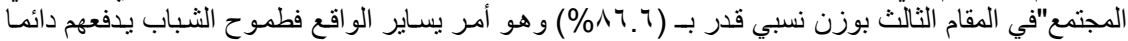

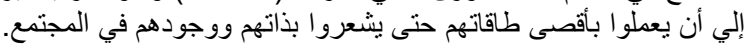

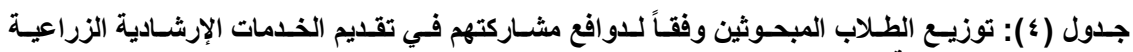
والمجتمعية

\begin{tabular}{|c|c|c|c|c|c|c|c|c|}
\hline \multicolumn{8}{|c|}{ درجه المشاركة ن= = } & \multirow{3}{*}{ دوافع المشاركة } \\
\hline \multirow[b]{2}{*}{ الترتيب } & \multirow{2}{*}{ النسبي } & \multicolumn{2}{|c|}{ ضعيف } & \multicolumn{2}{|c|}{ متوسط } & \multicolumn{2}{|c|}{ عالي } & \\
\hline & & $\%$ & |العدد & $\%$ & 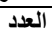 & $\%$ & 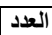 & \\
\hline 1 & $\Lambda \wedge . Y$ & 1.7 & r & $r \cdot r$ & $T \mathrm{~T}$ & 71. & AT & |- اكتساب بعض المهارات و الخبرات. \\
\hline r & NV. 9 & Y. & r & TI.1 & rA & 77.5 & A) & 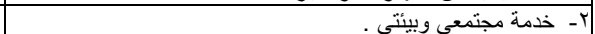 \\
\hline$\wedge$ & VI.r & $1 \Lambda^{\prime}$. & rt & $0 .$. & 71 & 41.9 & rq & | ل آ قضاء وقت فر اغي. \\
\hline$\varepsilon$ & $\wedge \varepsilon .7$ & $r . r$ & $\varepsilon$ & rq.r & $\varepsilon \wedge$ & $0 . r^{\prime}$ & $\mathrm{v}$. & ــ ـ توجيه طاقاتي نحو الأعمال الصالحة. \\
\hline $\mathrm{v}$ & VV.r & $9 . \cdot$ & 11 & $0 .$. & 71 & $\varepsilon \cdot .9$ & 0. & هـ ـ أكون قدوة لغيري من زملاني غير المقتتعين بالفكرة. \\
\hline$r$ & $\Delta 7.7$ & ๕.9 & 7 & $r \cdot r$ & $r{ }^{2}$ & $7 \varepsilon .1$ & $\mathrm{vq}$ & آح- الإحساس بوجودي كفرد في الَّجتمع. \\
\hline 7 & Ar.o & $1 r .9$ & IV & $r \leqslant .0$ & $r$ r. & $71 . \varepsilon$ & Vo & V- الحصول علي وظيفة في المستقبقل. \\
\hline 。 & AT.V & $\varepsilon .9$ & 7 & «. . & 01 & or.t & 70 & 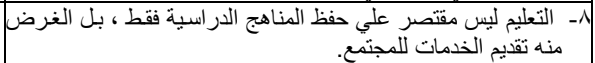 \\
\hline
\end{tabular}

رابعاً:الفوائد التي تعود علي الطلاب المبحوثين من المشاركة في تقديم الخدمات الإرشادية:

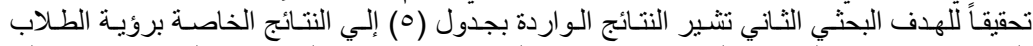

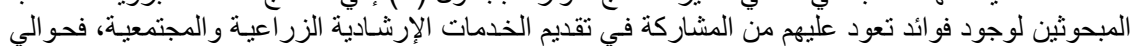

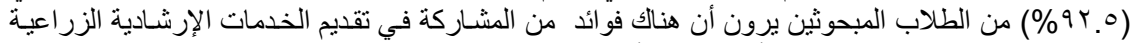

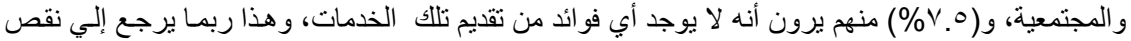
الدو افع الايجابية لدي بعض هض الثباب. 
جدول (0): توزيع الطلاب المبحوثين وفقاً لرويتهم حول وجود فوائد تعود عليهم من المشـاركة في تقديم

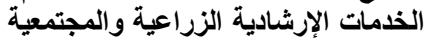

\begin{tabular}{|c|c|c|}
\hline$\%$ & العدد & وجود فوائد للمشاركة \\
\hline 94.0 & $M T$ & نعم \\
\hline$V .0$ & 1. & $\gamma$ \\
\hline $1 \ldots$ & ITr & الإجمالي \\
\hline
\end{tabular}

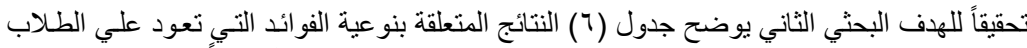

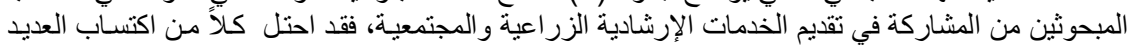

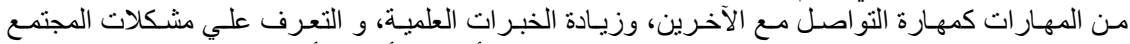

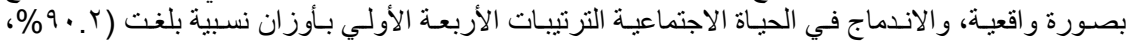

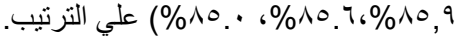

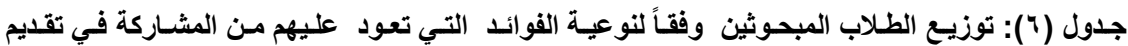
الخدمات الإرشادية الزراعية والمجتمعية ولئية

\begin{tabular}{|c|c|c|c|c|c|c|c|c|}
\hline \multicolumn{8}{|c|}{ درجة المنفعة ن= } & \multirow{3}{*}{ 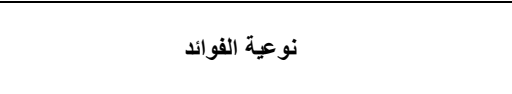 } \\
\hline \multirow{2}{*}{ الترتيب } & \multirow{2}{*}{ النسبي } & \multicolumn{2}{|c|}{ ضعيف } & \multicolumn{2}{|c|}{ متوسط } & \multicolumn{2}{|c|}{ عالى } & \\
\hline & & $\%$ & 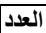 & $\%$ & العدد & $\%$ & 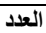 & \\
\hline 1 & $9 \cdot . r$ & 1.7 & r & rı.• & rt & VY.r & 19 & ا ـ اكتساب العديد من المهار ات كمهارة التو اصل مع الآخرين. \\
\hline$\Lambda$ & 87.7 & $1 \cdot .0$ & $\mid \pi$ & $\varepsilon \wedge . \vee$ & 7. & $\varepsilon \cdot .7$ & 0. & r- الحصول علي وظيفة مناسبة في المستقبل. \\
\hline r & 10.9 & r.t & $\varepsilon$ & ro.v & $\varepsilon \varepsilon$ & $7 \cdot .9$ & Vo & r- زيادة الخبرات العلمية. \\
\hline 7 & NI.r & V.r & 9 & «. & 01 & $01 . Y$ & Tr & عـ شغل وقتي في أعمال مفيدة \\
\hline$\varepsilon$ & 10. & Y. & $r$ & $r 9.1$ & $\sum 9$ & OV.V & V) & هـ الاندماج في الحياة الاجتماعية. \\
\hline r & 10.7 & 7.0 & $\Lambda$ & $r \cdot . \cdot$ & TV & $7 \Gamma . \varepsilon$ & $\mathrm{vA}$ & 7- التعرف علي مشكلات المجتمع بصورة و اقعية. \\
\hline 0 & Ar.q & IV.A & Yr & $r 9 . \wedge$ & $\sum 9$ & $0 . .2$ & $7 r$ & لا تبادل الخبراتِ و النصائح بين أفر اد المجتمع \\
\hline $\mathrm{V}$ & VV.V & $\Gamma \cdot . \Lambda$ & TA & rq. & ז & $\varepsilon \vee .9$ & 09 & 1- حب الناس وتوطيد العلاقات. \\
\hline
\end{tabular}

خامساً: تحديد احتياجات الطلاب المبحوثين للمشاركة في تقديم الخدمات الإرشادية الزراعية والماتئية المجتمعية:

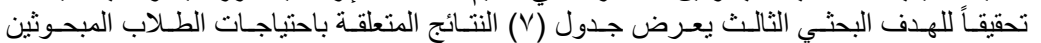

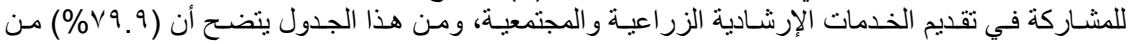

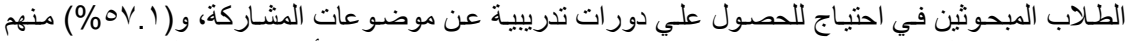

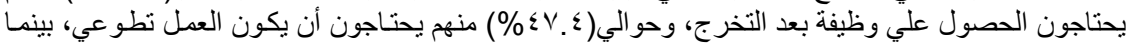

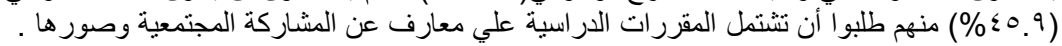

جدول (V): توزيع الطلاب المبحوثين وفقاً لاحتياجـاتهم المطلوبـة للمشـاركة في تقديم الخدمات الإرشـادية الزراعية والمجتمعية

\begin{tabular}{|c|c|c|}
\hline$\%$ & التكرار & الاحتياجات المطلوبة \\
\hline r.r & r & ا \\
\hline$\varepsilon \vee . \varepsilon$ & 74 & ا I- أن يكون العمل تطوعي . \\
\hline $11 . \cdot$ & $r \varepsilon$ & بـ العمل بمقابل مادي. \\
\hline$r \cdot . \wedge$ & §) & ــ الحصول علي درجات إضافية ( أنشطة فصلية). \\
\hline$\leqslant 0.9$ & 71 & هـ أن تشتمل المقرر ات الدراسية علي معارف عن المشاركة الإرشادية و المجتمعية وصور ها. \\
\hline $0 \vee .1$ & $V 7$ & T- أولوية الحصول علي وظيفة بعد التخرج. \\
\hline V9.V & 1.9 & V- الحصول علي دورات تدريبية عن موضو عات المشاركة. \\
\hline
\end{tabular}

جمعت وحسبت من استمارات الاستبيان

تبين نتائج جدول(^) مواصفات الدورات التدريبية التي يفضلونها الطلاب المبحوثين علي النحو الآتي:

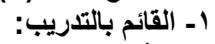

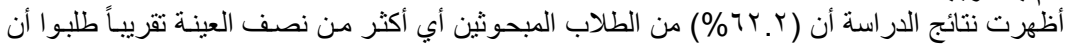

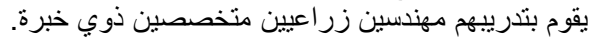


Ramadan, A. M. A.

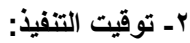

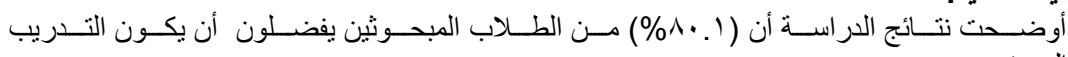

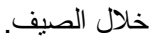

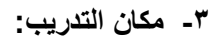

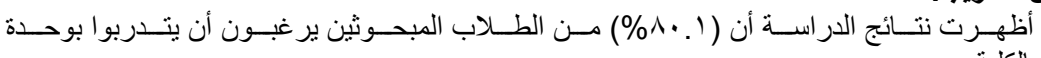

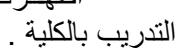

عـ أساليب التدريب المفضلة:

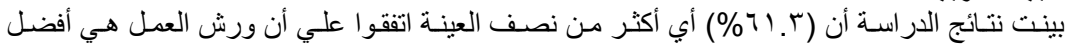

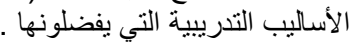

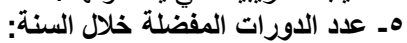

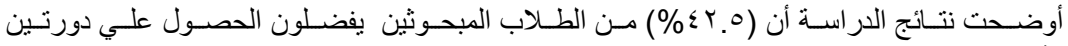

في السنة

צ- عدد أيام التدريب خلال الدورة الواحدة:

أظهرت نتائج الدراسة أن (

r إلي ع أيام للاورة اللواحدة.

V- عدد ساعات التدريب اليومية:

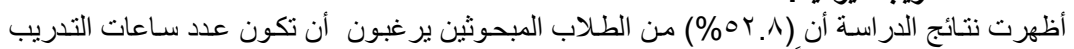

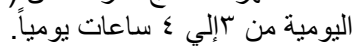

جدول (^): توزيع الطلاب المبحوثين وفقاً لمواصفات الدورات التوات التدريبية التي يفضلونها.

\begin{tabular}{|c|c|c|}
\hline$\%$ & العدد ن= 1 ( 1 & مواصفات الدورات التدريبية \\
\hline & & | - إلقائم بالتلتريب \\
\hline TV.V & $r \varepsilon$ & أساتذة بكليات الزر اعة. \\
\hline Tr. & 74 & مهندسين زر اعيين ذوي خبرة. \\
\hline 0.7 & 7 & استاتذة بكلية الزر اعة ومهندسين زر اعيين. \\
\hline & & ب آ توقيت التنفيذ \\
\hline$\lambda . .1$ & 10 & خلال الصيف \\
\hline 19.1 & Y & خلال الدراسة \\
\hline & & | بـ مكان التّاريب. \\
\hline$\lambda . .1$ & 10 & و وحدة التذريب بالكلبة. \\
\hline $9 . \varepsilon$ & 1. & مز ارع الإنتاج الحيو اني و الداجني. \\
\hline \&.V & o & مر مراكز البحوث الزراعية. \\
\hline 0.1 & 1 & إن مصانع الأغذية والألبان. \\
\hline & & ــ أسائيب التّريب المفضلة. \\
\hline 0.7 & 7 & ل محاضر ات نظرية. \\
\hline $7 . r$ & 70 & | ل ورش عمل . \\
\hline $1 \% .9$ & 19 & - (بوم حقل. \\
\hline 1.1 & r & محاضر ات نظرية ويوم حقل. \\
\hline Kr. & Ir & ورش عمل ويو حقل. \\
\hline $.9 \leqslant$ & $T$ & محاضر ات نظرية وورش عمل ويوم حقل. \\
\hline & & هـ عدد الدورات المفضلة خلال السنة . \\
\hline IV. & 11 & 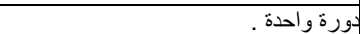 \\
\hline$\sum Y .0$ & \&o & 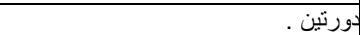 \\
\hline$\varepsilon .0$ & $\varepsilon r$ & آبالي؛ دورات. \\
\hline & & 7- عدد أيام التدريب خلال الدورة الواحدة. \\
\hline ro. 0 & KV & | إلى بيوم. \\
\hline$V \leqslant .0$ & $\mathrm{Vq}$ & 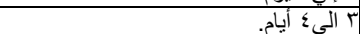 \\
\hline & & |V- عداد ساعات التّريب اليومية. \\
\hline$\varepsilon Y_{.}, Y$ & o. & | إلى ب ساعة. \\
\hline 0.1 .1 & 04 & | T إلي ع ساعات. \\
\hline
\end{tabular}




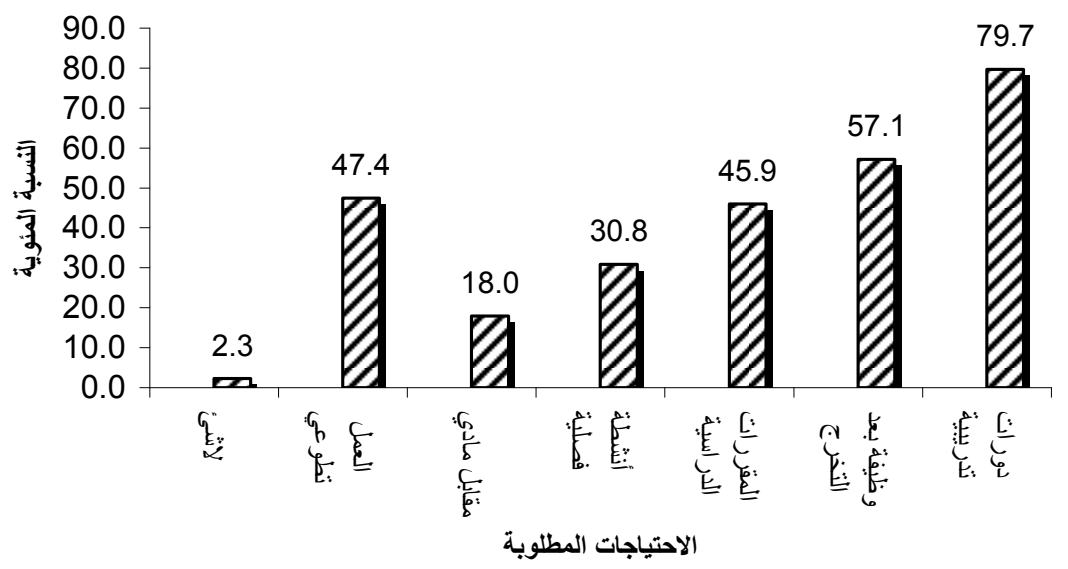

شكل (1) احتياجات الطلاب المبحوثين للمشاركة في تقديم الخدمات الإرشادية الزراعية والمجتمعية

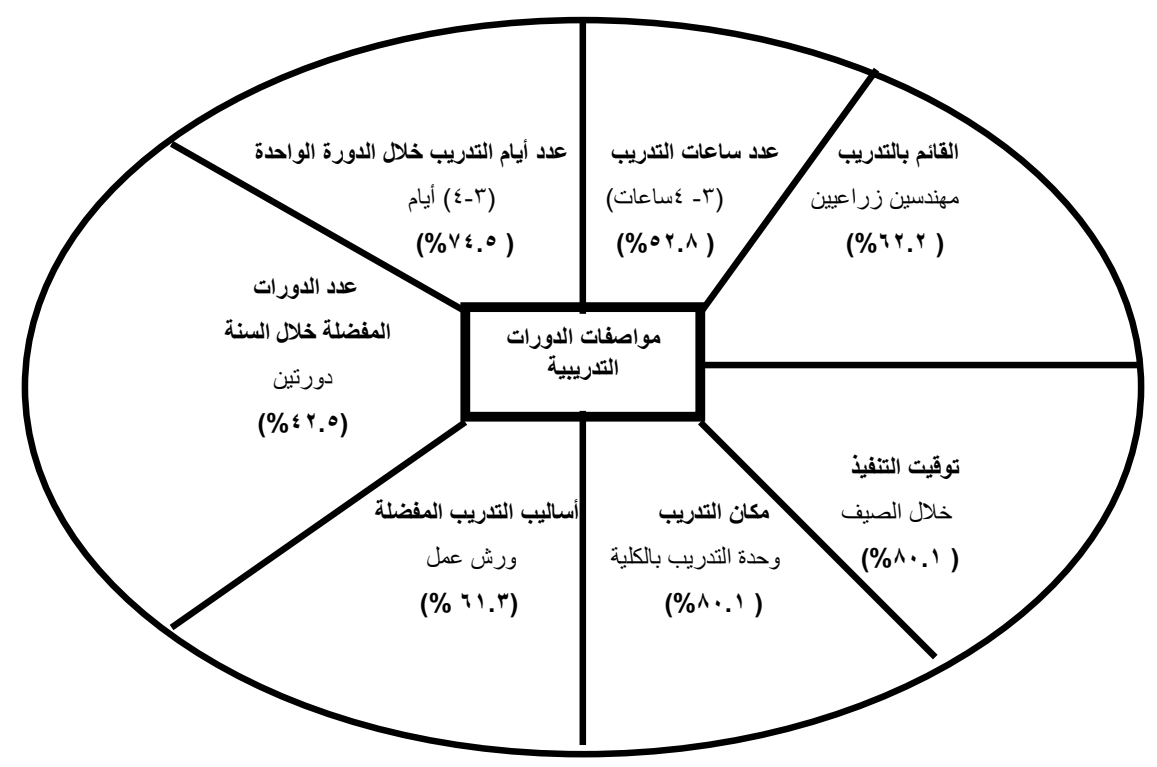

شكل (r) مواصفات الدورات التريبية التي يرغب الطلاب المبحوثين في الحصول عليها 
Ramadan, A. M. A.

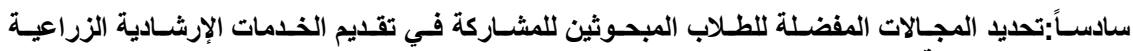

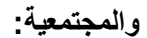

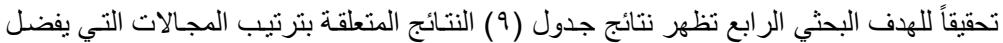

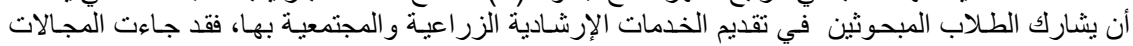

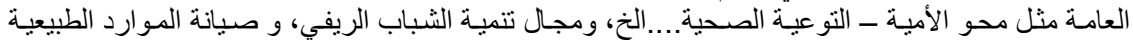

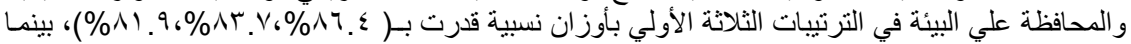

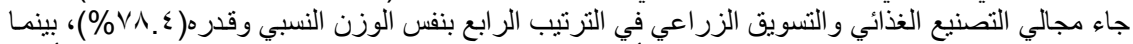

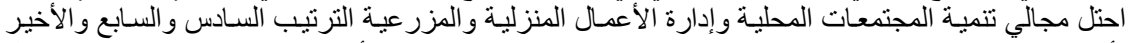

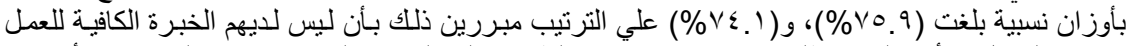

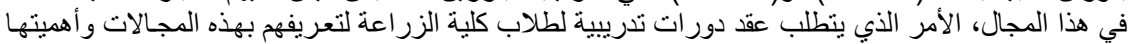

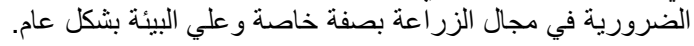

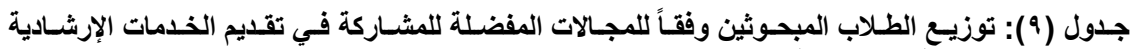

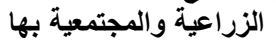

\begin{tabular}{|c|c|c|c|c|c|c|c|c|}
\hline \multicolumn{8}{|c|}{ الاستعداد للمشاركة ن= = TrT } & \multirow{3}{*}{ 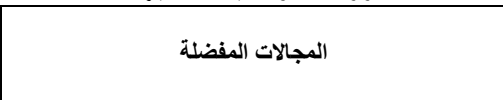 } \\
\hline \multirow{2}{*}{ الترتيب } & \multirow{2}{*}{ 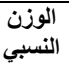 } & \multicolumn{2}{|c|}{ ضعيف } & \multicolumn{2}{|c|}{ متوسط } & \multicolumn{2}{|c|}{ عالي } & \\
\hline & & $\%$ & العدد & $\%$ & العدد & $\%$ & العدد & \\
\hline $\mathrm{v}$ & $V \varepsilon . \varepsilon$ & 7. & $\Lambda$ & $T \leqslant . Y$ & 14 & rq.r & rq & 1ـ إدارة الأعمال المنزلية والمزر عية. \\
\hline 7 & Vo. 9 & V.o & 1. & ov. 1 & $\mathrm{VT}$ & To.r & $\xi \mathrm{V}$ & r- بـ تنمية المجتمعات المحلية. \\
\hline r & Ar.V & $0 . \mu$ & $\mathrm{v}$ & $r \Lambda . \Gamma$ & 01 & $07 . \varepsilon$ & Vo & بـ إ- تتمية الثباب الريفي. \\
\hline$\varepsilon$ & $V \wedge . \varepsilon$ & А. ${ }^{\mu}$ & 11 & $\sum \wedge .1$ & $7 \varepsilon$ & $\varepsilon r .7$ & 01 & كـ إـ التصنيع الغذائي. \\
\hline$r$ & 11.9 & 1.0 & r & 01.1 & 71 & $\varepsilon \vee . \varepsilon$ & $\pi$ & 0- صبانة الموارد الطبيعية والمحافظة علي البيئة \\
\hline$\varepsilon$ & $V \wedge . \varepsilon$ & V.o & 1. & $\sum 9.7$ & 77 & $\varepsilon r .9$ & or & דـ التسويق الزراعي. \\
\hline 1 & ง५. $\varepsilon$ & 1.0 & r & TV.T & o. & 7.99 & 1) & 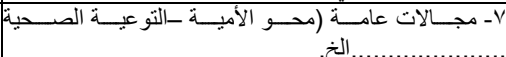 \\
\hline
\end{tabular}

سابعاً:تحديد الفئات التي يرغب الطلاب المبحوثين في التعامل معها:

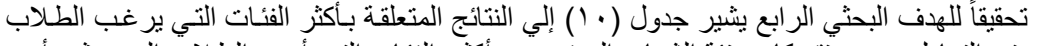

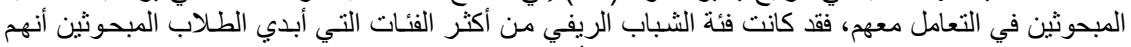

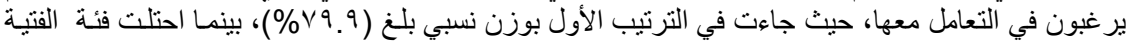

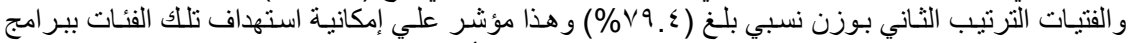

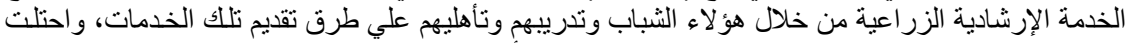

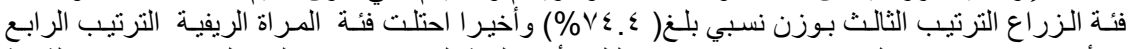

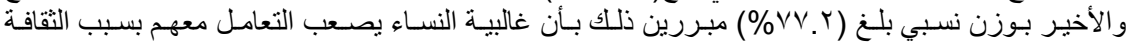

المجتمعية.

جدول ( • (): توزيع الطلاب المبحوثين وفقاً لتفضيلاتهم لأكثر الفئات التي يرغبون في التعامل معها

\begin{tabular}{|c|c|c|c|c|c|c|c|c|}
\hline \multicolumn{8}{|c|}{ الاستعداد للتعامل ن= IT } & \multirow{3}{*}{ الفئات المدروسة } \\
\hline \multirow{2}{*}{ الترتيب } & \multirow{2}{*}{ النسبي } & \multicolumn{2}{|c|}{ ضعيف } & \multicolumn{2}{|c|}{ متوسط } & \multicolumn{2}{|c|}{ عالي } & \\
\hline & & $\%$ & العدد & $\%$ & العدد & $\%$ & العدد & \\
\hline$\varepsilon$ & V..1 & 9.. & IT & $0 . \varepsilon$ & TV & $\varepsilon \cdot .7$ & $0 \leqslant$ & | - المر أه الريفية. \\
\hline r & $V Y . \varepsilon$ & $0 . r$ & $\bar{v}$ & 0.1 & $\mathrm{~V} / \mathrm{T}$ & TV.T & 0. & إك- الزراع. \\
\hline 1 & 19.9 & 7.1 & 9 & $\sum 7.7$ & Tr & $\leqslant 7.7$ & TY & |r الثـباب الريفي. \\
\hline r & $V 9 . \varepsilon$ & 10. & $r$. & $\Gamma .7$ & $\leqslant r$ & or. & $W_{1}$ & 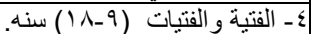 \\
\hline
\end{tabular}


ثامنـاً: تحديد المعوقـات التـي تحـول دون المشـاركة في تقديم الخدمات الإرشـادية الزراعيـة والمجتمعيـة من

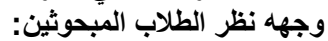

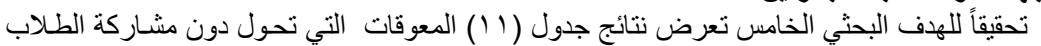

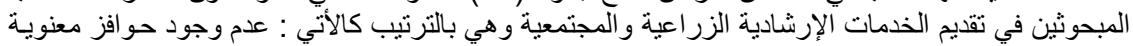

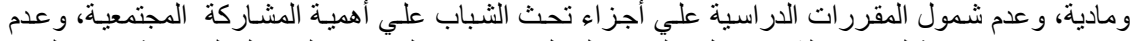

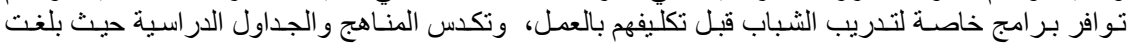

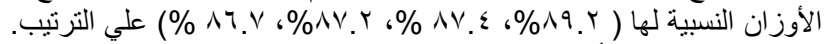

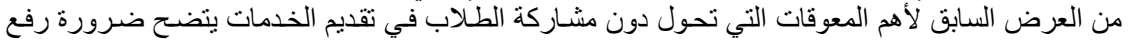

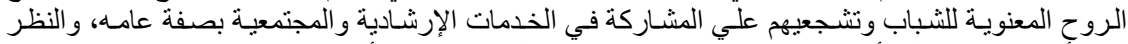

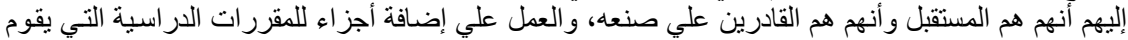

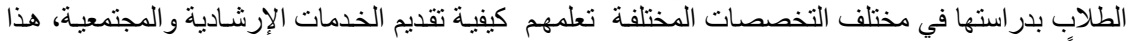

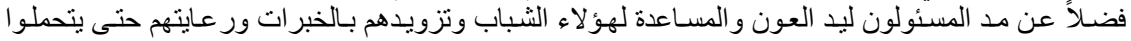

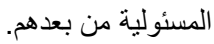

جدول (1 ا ): توزيع الطلاب المبحوثين وفقاً لـروئهم لأهم المعوقات التي تحول دون المشـاركة في تقديم الخدمات الإرشادية الزراعية والمجتمعية

\begin{tabular}{|c|c|c|c|c|c|c|c|c|}
\hline \multicolumn{8}{|c|}{ درجة تواجد المعوق ن=بr Ir } & \multirow{3}{*}{ 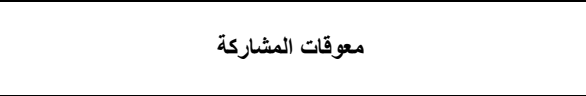 } \\
\hline \multirow{2}{*}{ الترتيب } & \multirow{2}{*}{ 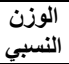 } & \multicolumn{2}{|c|}{ ضعيف } & \multicolumn{2}{|c|}{ متوسط } & \multicolumn{2}{|c|}{ 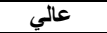 } & \\
\hline & & $\%$ & 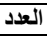 & $\%$ & 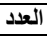 & $\%$ & 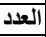 & \\
\hline 1 & ᄉ9. $\mathrm{r}$ & $0 . r$ & $\mathrm{~V}$ & YI.A & rq & $V Y .9$ & $9 V$ & |- عدم وجود حو افز معنوية ومادية. \\
\hline 7 & 11.9 & $\varepsilon .0$ & 7 & $\sum 0.1$ & 7. & $0 . .5$ & $7 V$ & بـ - نقص المعلومات عن مجالات الخدمة الإرشادية \\
\hline$\wedge$ & 17.9 & IT.A & IV & $\varepsilon r .7$ & 01 & $\varepsilon r .7$ & $0 \wedge$ & ب- عدم توفر الوقت الكافي للقيام بتلك الأنشطة. \\
\hline$\varepsilon$ & $\wedge\urcorner . \vee$ & .9 & IT & rI.A & rq & 79.4 & 94 & ع ـ تكدس المناهج و الجداول الدر اسية وحضور الكلية طو ال الأسبوع. \\
\hline 0 & ᄉ५. $\mathrm{r}$ & $\cdot . \wedge$ & 1 & $r 9.1$ & or & 09.5 & $\mathrm{Vq}$ & 0ـ نظرة بعض المسئولين للثباب علي أنهم غبر فعالين في المجتمع. \\
\hline r & AV.Y & $r . \Lambda$ & 0 & $r \cdot . \wedge$ & \&1 & 70.2 & $\Lambda \mathrm{V}$ & آ- عدم تو افر بر امج خاصة لتدريب الثباب قبل تكلبفهم بالعمل. \\
\hline r & $\Lambda V_{\text {. }} \varepsilon$ & r.r & $r$ & r. & $\varepsilon \leqslant$ & $7 \varepsilon . V$ & 17 & |لمشاركة المجتمعية المقرات الدراسية علي أجزاء تحث الثباب علي أهمية \\
\hline $\begin{array}{l} \\
\end{array}$ & $V V .7$ & 17.0 & rt & rT.A & $\sum 0$ & $\varepsilon 9.7$ & 77 & لــ افتقاد الشباب لبعض مهار ات التو اصل مع الآخرين. \\
\hline
\end{tabular}

تاسعاً: تحديد المقترحات التي تحفز الطلاب المبحوثين علي المشاركة في تقديم الخدمات الإرشـادية الزراعية

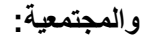

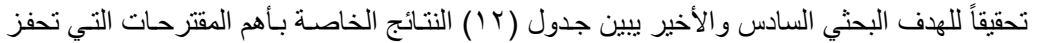

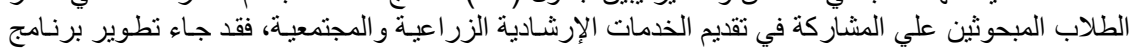

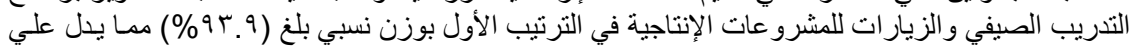

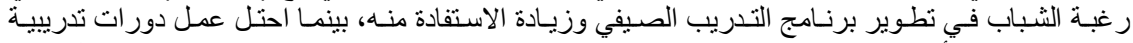

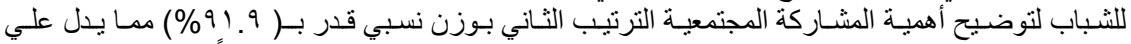

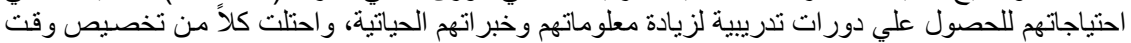

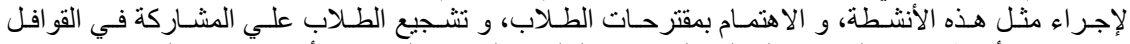

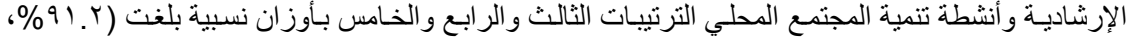

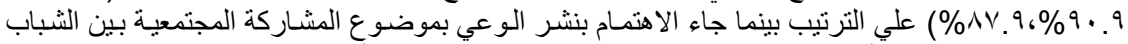

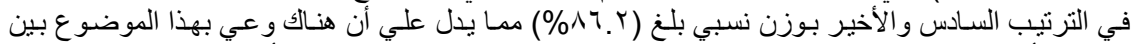
الثباب وأهميتة ولكن ينقصهم توفير المحفزات التي تساعدهم علي القيام بمثل هذه الأنشطة. 
Ramadan, A. M. A.

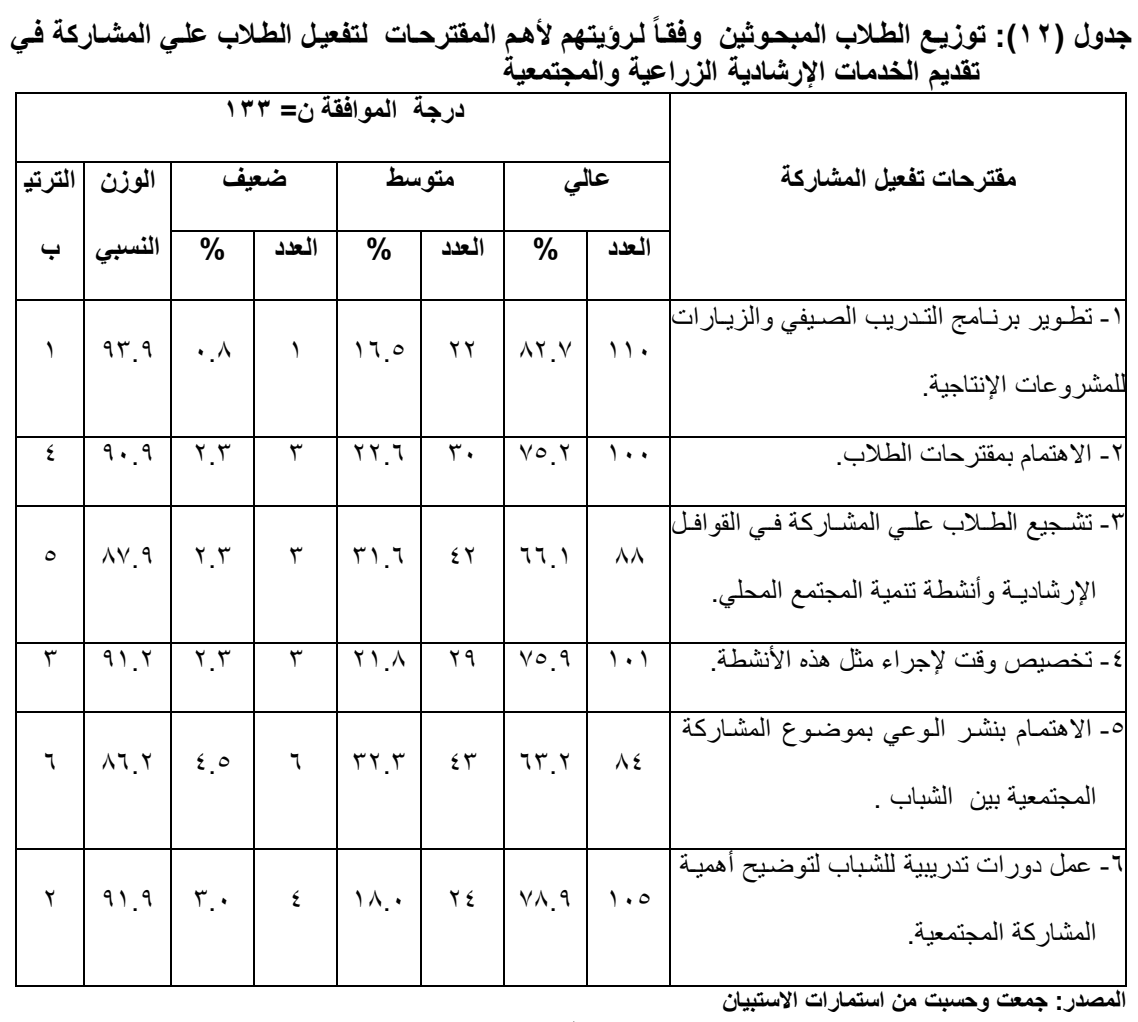

\section{التوصيات}

في ضوء ما توصلت إليه الدراسة من نتائج توصي بالآتي:

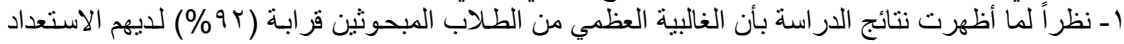

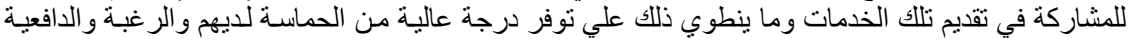

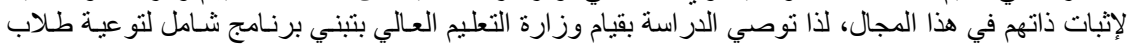

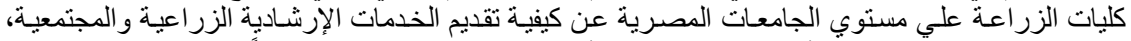

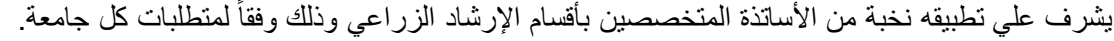

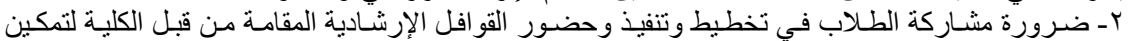

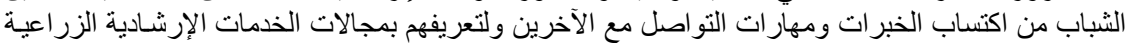

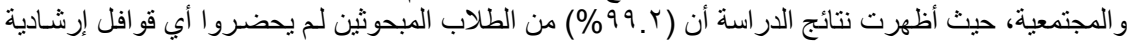
من قبل. r- الاهتمام بعقد دورات تدريبية مكتفة للطلاب في مجالات تقديم الخدمات الإرشـادية الزر اعية و المجتمعية،

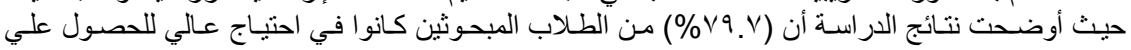
دور ات تدريبية لكي يشاركو ا في تقديم تللك الخدمات.

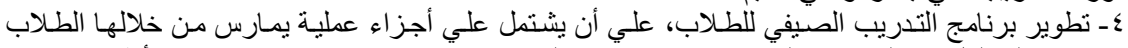

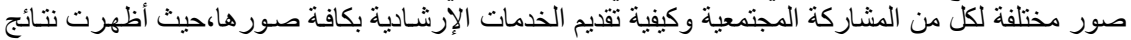

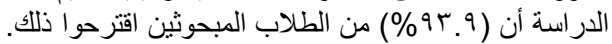

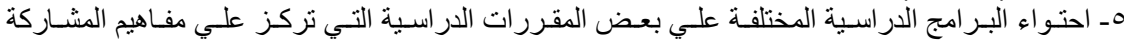

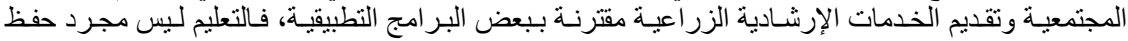

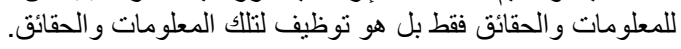




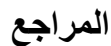

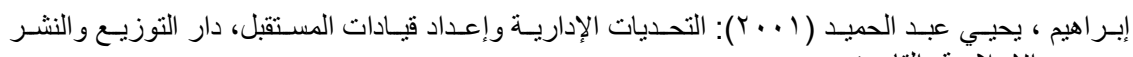

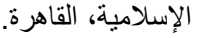

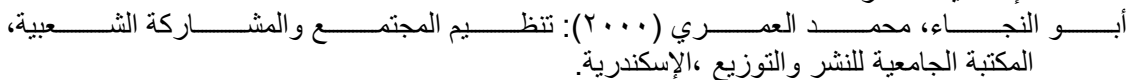

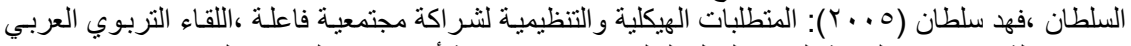

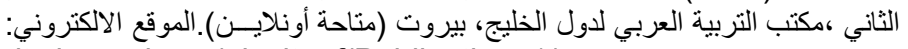

http://faculty.ksu.edu.sa/alsultanf/Publications1/

Visited in:12-7 -2014

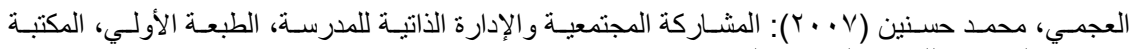

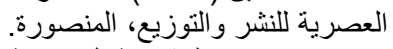

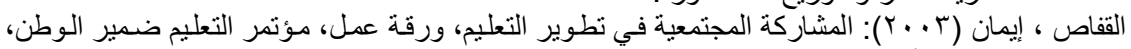

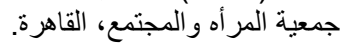

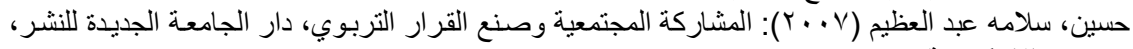

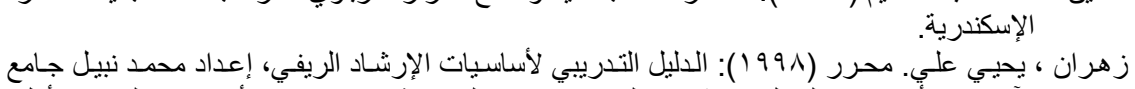

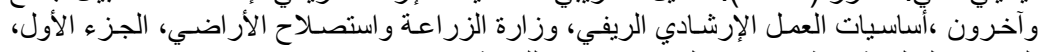

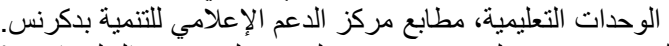

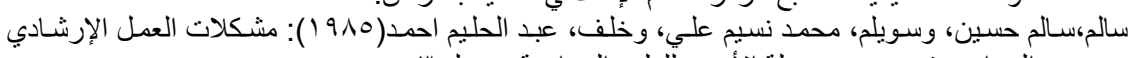

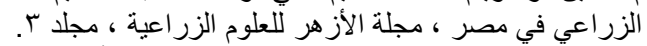

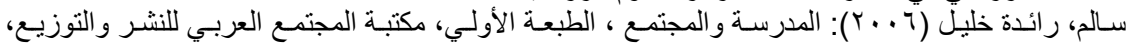

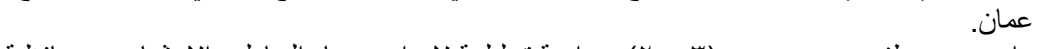

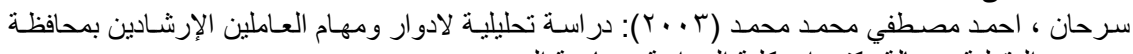

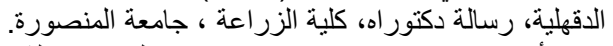

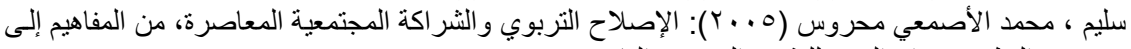

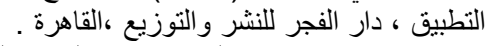

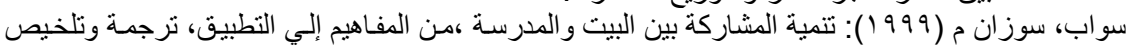

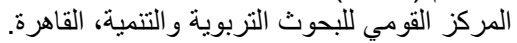

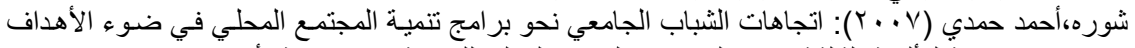

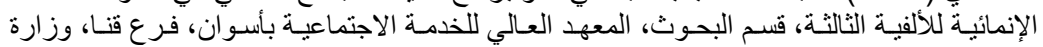
التعليم العالي.

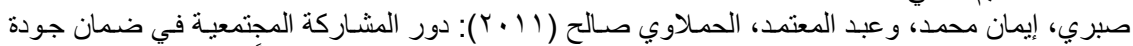

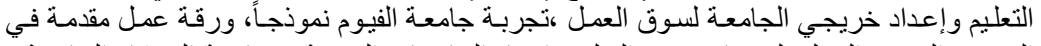

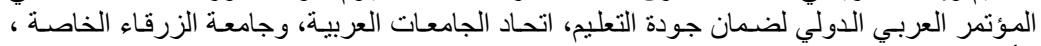
الأردن (متاحة اونلاين ). علي الموقع الالكتروني:

http://www.alazhar.edu.ps/Planning/Planning\%20Academic\%20quality2013/i mages/lib-arb/29.pdf

Visited in:1 -12-2014

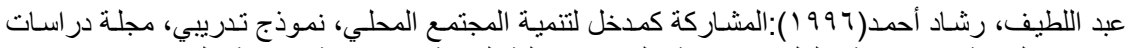

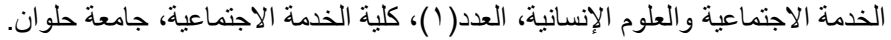

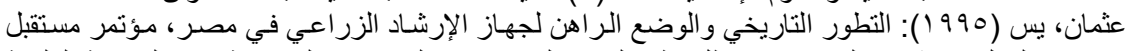

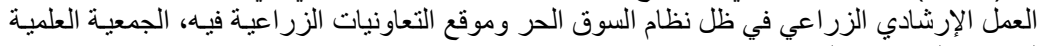

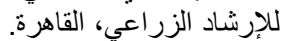

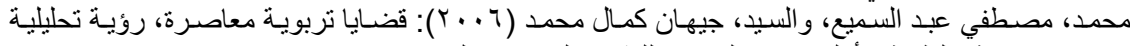

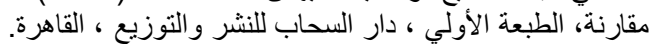

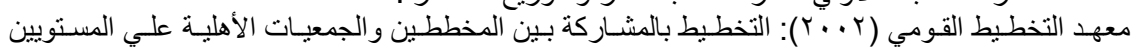

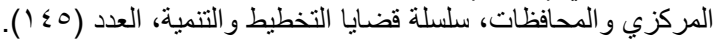


ـ مركز مـوارد التنميـة ( • ( ب): الدليل التدريبي، التتميـة بالمشـاركة، القـاهرة (متاحسة أونلاين).علي الموقع

http://www.slideshare.net/RDC2/ss-5314119 الالكتروني:

Visited in:25-11-2014

Andolina, M. W; Jenkins, K; Keeter, S. and Zukin, C. (2002). Searching for the meaning of youth civic engagement: Notes from the field. Applied Developmental Science, 6(4).

Clary, E; Snyder, M. and Ridge, R. (1992): Volunteers' motivations: A functional strategy for the recruitment, placement, and retention of volunteers. Nonprofit Management and Leadership, 2(4).

\title{
AN EXPLORATORY STUDY OF WILLINGNESS OF THE FACULTY OF AGRICULTURE STUDENTS AT MANSOURA UNIVERSITY TO PARTICIPATE IN PROVIDING THE AGRICULTURAL EXTENSION AND COMMUNITY SERVICES. Ramadan, .A. M. A. \\ Agricultural Extension and Rural Society, Faculty of Agriculture, Mansoura University
}

\begin{abstract}
The study aimed to identify the degree of willingness of the faculty of agriculture students at Mansoura university to participate in providing the agricultural extension and community services. Data were collected from April 2014 to May 2014 by using personal interview questionnaire on an accidental sample (133) from students of the Faculty of Agriculture at Mansoura University. Frequency, percentage and relative weight methods were used to statistically analyze data and explain the results.

The most important results of the study could be summarized as follow:

1- the most students have been willingness to participate in providing agricultural extension and community services with a percentage of $91.7 \%$. The motivation for participation is acquisition of some skills and experiences, which got the first rank with a relative weight value of $88.7 \%$.

2- the majority of students believe that there are benefits from participation in providing agricultural extension and community services with a percentage of $92.5 \%$. the most benefits from participation in providing agricultural extension and community services is achievement of many skills which were firstly ranked with a relative weight value of $90.2 \%$.
\end{abstract}


3- the students needed to training courses for participation in providing agricultural extension and community services with a percentage reached $79.7 \%$.

4- the general fields, such as literacy, health awareness, ... etc. were firstly ranked with a relative weight value of $86.4 \%$ in the field of providing the agricultural extension and community services. The rural youth were firstly ranked as a targeted category with a relative weight value of $79.9 \%$.

5- lack of moral and financial incentives achieved the first rank with $89.2 \%$, which were the most problems hampered the diffusion of the idea.

6- the development of summer training program and visits to the productivity projects were the most important proposals motivating youth to participate in providing agricultural extension and community services, which were firstly ranked with $93.9 \%$. 